\title{
Enterprise information behavior's effect on the customer behavior response based on the network community
}

\author{
Dong Zejia ${ }^{1,2, a}$, Sun Duo ${ }^{1}$ and Sun Xiao ${ }^{1,2}$ \\ ${ }^{1}$ JiLin University of Finance and Economics, Changchun 130117, China \\ ${ }^{2}$ Jilin Province Key Laboratory of Internet Finance, Jilin University of Finance and Economics, Changchun 130117, China
}

\begin{abstract}
Constructs the three-dimensional framework of enterprise information behavior based on online community, explains the connotation of enterprise information behavior at different latitudes; again, put forward the concept of customer response, carried on the dimensions and the analysis of connotation. Finally, deeply discussed the impact of enterprise information behavior on customer response based on the network community.
\end{abstract}

\section{Introduction}

Network community is the core product of WEB2.0 technology, and it is also a virtual reality society in the network world. In the context of network communities, customers can participate the content of manufacturing, which makes customers no longer satisfy the act as a passive acceptance of information role, in addition, the customer to get more business information, and want companies to be able to listen to their voice and demand for products, also willing to share the experience for their use of the product and others. At the same time, after the information demands of customers have been concerned about the quantity and quality of information, gradually entered a stage of "perceptual demand". In the "perceptual demand" stage, the concern of customer is not the quantity and quality of information, but the degree of anastomosis between information and their own needs. Customer requirements on information in the purchase of products may no longer just get some physical attributes of the product itself, more is to obtain a psychological craving and emotional satisfaction through behavior information or business information. More is to obtain a kind of emotional desire and psychological satisfaction through the information or the information behavior of the enterprise. Specific performance in them except whether attention information content can bring their knowledge level, such as the authenticity, integrity, value, and pay more attention to their own experience in the process of information acquisition, such as timeliness, convenience and fluency.

Network community provides a new platform for enterprises to effectively use information resources to strengthen the customer response, and make good use of network community will become the inevitable trend of information communication between enterprises and customers to meet the needs of customers' information.
This study will build a framework of enterprise information behavior under the network community environment, and explore the impact of enterprise information behavior on customer response.

\section{The construction of enterprise information behavior under the network community environment}

Wilson believes the information behavior is the sum of human behavior and the related information sources and channels of information, including active and passive information seeking and information utilize [1], $\mathrm{Hu}$ Changping believes that information behavior is a kind of human specific behavior, refers to the subject in order to meet the specific information needs, showing in the external effect under the stimulation of the acquisition, search, exchange, transmission, absorption, processing and use of information [2]. This study will define the enterprise information behavior under the network community environment as follows: the concept of enterprise information behavior is refers to the enterprise to meet customer information demand, the total of a series of behavior actively engaged in information dissemination, exchange and use on network community, including three dimensions: enterprise information release behavior, enterprise information response behavior and enterprise information seeking behavior.

\subsection{Enterprise information release behavior}

Xie Yi and PengSiqing [3] think the enterprise public information act for a product, service, business organizations and individuals, to release the news through print, radio or other media to spread word-of-mouth. Wang Guilan believes that the enterprise public

$\overline{\text { a Corresponding author: dongzejia } @ j l u f e . e d u . c n}$ 
information is the enterprise and its customers or the news media, such as the subject of information, there is a destination of publicity about the company or brand attributes and events for the purpose of publicity [4]. In this paper, the concept of enterprise information release behavior is defined as follows: enterprises use self built network community to actively promote the corporate or brand related information to the community customers. And the enterprise information content is divided into: enterprise basic information, product function information, product service information, enterprise activity information, social responsibility information. Enterprise information release mode can be included in the placement of advertising, manufacturing topics, writing blog three categories and so on.

\subsection{Enterpriseinformation response behavior}

Under the traditional environment, Customer feedback information and enterprise information feedback responses and solutions to customers in a relatively closed environment, the whole process only by customer who feedback and enterprise involved, whether the enterprise to the customer feedback information timely response, the content is correct answers are only on the involved customers have an impact, but for other customers have little effect, enterprises do not pay attention to the customer feedback. The network community is an extremely open network platform, the information in the network community can be all the communities within the community to know and quickly spread. Therefore, enterprises must pay high attention to the feedback of customer, we will use enterprise information response behavior to express the respond to customer feedback on the network community. The behavior of response to emphasis on whether the enterprise response customer feedback, mainly reflected in the reaction time and attitude etc., and an answer emphasis on the effect of answer customer feedback information, mainly embodied in the answer to solve the problem is to make customer satisfaction.The content of enterprise information response behavior can meet the customer's information needs. Response time from the customer feedback time is short of the business more attention to customer feedback information; response attitude is mainly reflected in the use of language, information form selection and other details, good attitude response will bring customer intimacy.

\subsection{Enterprise information seeking behavior}

Enterprise information seeking behaviors an enterprise to use network community detection and ask customer information inquiries. Enterprise information seeking behavior of network community environment consists of two parts including information detection and information inquiry form. The information detection is likely related to customer privacy and easy to induce customers off problems, to obtain the customer demand information through indirect means, the enterprise information inquiry function through the application of network community to communicate directly with the customer, ask inquiries related information from customer. Enterprises actively communicate with customers, not only can effectively access to customer demand information, but also more important is to maintain the relationship between customer and enterprise stability, enhance customer satisfaction and trust of enterprise brand.

\section{Customer response concept and dimension division}

E. Bucklin Sunil, Gupta S., Siddarth Randolph believes that customer response is decisions to determine the customer's brand, purchase rate, the number of purchase [5]. A. Martin Melissa study shows that consumers respond to the use of the product, including psychological response and behavioral responses [6]. Bhattacharya Sankar and Sen C.B. make the consumer response to divided into internal and external response. Internal response, such as the consumer's perception, attitude and attribution of corporate social responsibility activities; external responses, such as purchasing behavior and loyalty [7]. According to the definition and the research purpose of this study, customer response will be further divided into customer psychological response and customer behavior response, the customer psychological response is psychological response of customer of the enterprise information under network community environment, use the "customer perception" and "customer experience" to explain; customer behavior response refers to the behavioral response of customer to the enterprise information behavior under network community environment, use the "customer participation" and "customer word-of-mouth" to explain.

\subsection{Customer perception}

Mitra and Golderls believe that the customer perceived quality is derived from the customer's own or other people's experience and related marketing information, its formation does not depend on the use or inspection of the product [8]. XieXiaofei and XuLiancang that customer perceived risk is customer perceived in the transaction process of the risks that may exist, they focus on risk of customers by intuition and experience from the external environment in the judgment of the subsequent behavior [9]. In this study, the definition of customer perception is defined as the concept of customer perception, customer perception and subjective evaluation of enterprise information behavior in the network community environment.

\subsection{Customer experience}

Wang Tao and Cui Guohua believe that the customer experience is a beautiful and profound feeling in the consumer context of the enterprise, as a result of participation in the design, to assist in promoting and immersion in the process of feeling the entire consumption process [10]. GuoHongli believes that the 
customer experience is the impact and influence of the enterprise to the customer psychology in the process of interaction between customers and enterprises [11].This research defines the customer experience as the customer's perception of the enterprise information behavior in the network community environment, such as intuition, emotion, and so on, as well as intelligence, thinking and so on.

\subsection{Customer participation}

Customer participation is an essential component of customer behavior response. Kelley, Donnelly $\mathrm{Jr}$ and Skinner point out that customers can participate in the service of the enterprise in order to obtain the service related information and provide the information, and customer participation will affect the service products of the enterprise [12]. Lloyd thinks that customer participation is made by the customer in the service process of the contribution, will ultimately affect the service and quality of service they accepted [13]. In this study, customer participation is divided into two parts, the first part is the construction of customer participation in the network community more, such as registration, post or blog, in the second part is more with enterprise information interaction, including customer of business information browse, comment, forwarding and other participation behavior.

\subsection{Customer word-of-mouth}

XuLihua point out that customer word-of-mouth is equivalent to the customer recommendation, refers to a certain organization credit and trustworthiness, business methods, service and other aspects of the information, it can communicate between the public through mutual communication, from one customer to another customer, the formation of a product or service term unified and stable views[14]. Huang Xiaojun and XuWeiqing believe that word-of-mouth is a non-commercial and recipient of perceived information about a product, brand, organization and service of informal interpersonal communication [15]. In this paper, according to the research needs to define customer word-of-mouth as the customer through the enterprise network community to spread the brand of the positive word of mouth.

\section{The impact of enterprise information behavior on customer response}

Enterprise information is a special kind of product or service, it does not be used to measure with price, also won't transaction to customer. But it has a huge value, it influences and changes the customer's perception and experience to the brand, and then determine the customer's brand choice, purchase decision-making and post purchase feedback and other acts.

Customers purchase products or services, will have a psychological expected risk, it namely buy this brand of products or services may bring some aspects or some degree of lost, the expected risk from unknown or uncertain to purchase object and purchasing environment. The customer in order to eliminate or reduce the risk of this expected level, the usual practice is through various channels to search and obtain the related information, to increase their own cognition of purchasing object and purchasing environment depend on the information content. The more comprehensive information the customer gets, the higher the credibility and the shorter the time to spend, the more you know about the product or service of the brand, the more you trust your own judgment and make the right decision. One of the purpose of enterprise information behavior under the network community environment, is through actively for customers to provide high quality information to eliminate or reduce the expected risk which customers appear in the purchase process and reduce the time cost of acquiring customer information, the behavior of the active enterprises impact of customer perceived and experience for different aspects.

Enterprise information release behavior can reduce customer perceived risk effectively. The basic information of the enterprise can make the customer fully understand the basic situation and the growth path of the enterprise or the brand. The product information and service information make customers quickly obtain the required purchase products and related services, strengthen the understanding of the customer to buy the basic content of the basic attributes of the product and related services, understand the broader scope, the degree of customer perceived risk is smaller. Enterprise social responsibility information, to allow customers to perceive the enterprise has the correct values and as a member of the community should have a sense of responsibility and mission. Information release mode and information form can enhance the customer experience effect.

Information release mode and information form can enhance the customer experience effect. In the form of business information under the traditional media environment release and presentation of relatively simple form, newspapers and magazines of the information presented in the form of words and pictures, broadcasting the information presented in the form of audio, information of TV is presentation for video form. A single form of information is not conducive to get the smooth experience for customer. In the network community environment, enterprises can use a variety of network community applications, through different ways to release information, and each form of information can be presented in the form of multiple categories of information. A variety of information release mode and multiple information form can stimulate customer's sensory experience in many ways, and can deepen the understanding and memory of information content.

Information content in enterprise information release behavior is usually common and common information content. However, for the information content of different customer needs and concerns are not the same, they encountered problem of product in the process of use is different, therefore the enterprise information release behavior can not meet all the information needs of all customers. When customers can not meet their personal 
information needs through the information released by the enterprise, they usually get their own unique information needs and problems by the way of active inquiry. Enterprise's information response behavior is an effective supplement to the enterprise information release behavior, it can meet the customer personalized information needs. Enterprise information response speed, attitude, etc. can not only meet customer personalized information needs, but also from the emotional aspects of customer favor of enterprise, influence customer experience effect, customer participation degree and the quality of customer word-of-mouth. It is a form of enterprise information response behavior also is the enterprise information and customer interaction, enterprise information seeking behavior of network community environment mainly has two aspects, one is through the network community function, proposes a leading question set to obtain customer information, this information is usually the customer privacy information. For example, when the customer $\log$ in online community before the need for personal information registration, in the network community, some customers can participate in the activities of the plate also need to fill some information such as customer information. On the other hand is through the network application function of community in order to obtain customer inquiries real-time customer demand information, these problems usually include customer evaluation, product or service customers want to products or services. Enterprises actively communicate with customers, can produce a good customer psychological response.

Enterprise information release behavior is the behavior of enterprises to take the initiative to the brand related information to the customer's behavior, the enterprise for the information content and the release of the way with controlling ability. When the information expressed by enterprises is rich in information, the information is displayed in the form of novel, information dissemination way, customers can more easily access to information, and is willing to comment and share enterprise information. The comments of customer expressed their attitude towards the brand for enterprise information display content, form and mode of transmission, this attitude is a form of expression of customer word-of-mouth; customer for enterprise information sharing, which is a form of customer participation, when the enterprise information has obvious tendency to attract customers, customers will share the enterprise information easier in network community.

Enterprise information response behavior and information seeking behavior itself is the result of customer participation, so as to inquire the information behavior response behavior of enterprises and community information can meet customer information demand and make the customer satisfied, customers are more willing to have contact and exchange of information through the network of community. At the same time, customers will take the initiative to put themselves on the response behavior of enterprise information and inquire a good impression to others, and encourage others to recommend the brandor products to others.

\section{Conclusions}

This paper synthesizes the related concept of information behavior, defines the concept of enterprise information behavior, explain the connotation of enterprise information behavior from the three dimensions including information release behavior, information response behavior and information seeking behavior. Then the customer response is divided into two levels, including the customer's psychological response behavior and customer behavior response, including customer perception, customer experience, customer participation and customer word-of-mouth. Finally, based on the existing literature, the influence of enterprise information behavior on customer response is discussed in the network community environment, so as to provide theoretical reference for the improvement of enterprise's information behavior quality.

\section{Acknowledgments}

The research was supported by the open fund project from Key Laboratory of Logistics industry economy and intelligent logistics at universities in Jilin Province (project number is 02060312; 02060311), and was supported by the key project of JiLin University of Finance and Economics (project number is 2016Z01).

\section{References}

1. T. D. Wilson, Informing Science, 3, 49-55 (2000).

2. C. P. Hu, Research on modern information management system, 2004.

3. Y. Xie, S. Q. Peng, Nankai business review, 12, 71-80 (2009).

4. G. L. Wang, C. Q. Zhang, Consumer Economy, 10, 65-68 (2011).

5. R. Bucklin, S. Gupta, S. Siddarth, Journal of Marketing Research, 189-197 (1998).

6. M. A. Martin. Advances in Consumer Research, 29, 249-250 (2002).

7. C. B.Bhattacharya, S. Sankar, California Management Reciew, 1, 9-24 (2004).

8. D. Mitran, P. N. Golder, Marketing Science, 25, 230-247 (2006).

9. X. F. Xie, L. C. Xu, Dynamic Psychology, 3, 15-18 (1995).

10. T. Wang, G. H. Cui, Economic management, 20, 43-49 (2003)

11. H. L. Guo, Industrial engineering and management, $\mathbf{3}$, 119-123 (2006).

12. L. Keller, Journal of Marketing, 57, 1-29 (1933).

13. A. E. Lloyd, The role of culture on customer participation in services, 2003.

14. L. H. Xu, Jiangsu business theory, 10, 147-148 (2003).

15. W. Q. Xu, Journal of Zhejiang University (Social Sciences Edition), 34, 125-132 (2004). 